\title{
Serogrouping Neisseria gonorrhoeae: Correlation of coagglutination serogroup WII with homosexually acquired infection
}

\author{
KATHERINE G REID AND HUGH YOUNG \\ From the STD Diagnostic Laboratory, Department of Bacteriology, University Medical School, \\ Edinburgh
}

SUMMARY With coagglutination reagents prepared against W antigens, 205 clinical isolates of Neisseria gonorrhoeae were classified into three serogroups WI, WII, and WIII. Of 195 strains isolated from patients who acquired their infection in the Edinburgh area, $85(44 \%)$ belonged to serogroup WI and $110(56 \%)$ to serogroup WII. Serogroup WII accounted for $90 \%$ of all isolates from homosexual men and for $34 \%$ and $47 \%$ of isolates from heterosexual men and women respectively $(p<0.001)$. In homosexual men serogroup WII predominated regardless of the anatomical site from which the strain was isolated, and accounted for $94 \%$ of rectal, $90 \%$ of urethral, and $81 \%$ of pharyngeal isolates.

\section{Introduction}

The serological classification of Neisseria gonorrhoeae by coagglutination was first developed by Sandström and Danielsson.' Although these workers described three different antigen classes, $W$, $\mathrm{J}$, and $\mathbf{M}$, only the $\mathrm{W}$ antigens proved suitable for serogrouping $N$ gonorrhoeae. Reactions with W reagents were not altered by changes in colonial morphology and were shown to be stable, reproducible, and resistant to periodate. With reagents prepared against $\mathrm{W}$ antigens, gonococcal strains could be classified into three serogroups WI, WII, and WIII.

Recent work ${ }^{3}$ has shown that these coagglutination $W$ serogroups correlate with the serotyping system of Buchanan and Hildebrandt ${ }^{4}$ based on antigenic differences in purified outer membrane protein I. Serogroups WI and WII/WIII correspond to two mutually exclusive forms of outer membrane protein I, protein IA and protein IB. ${ }^{3}$ It appears that serogroup WIII represents a minor but prominent antigenic variant of protein IB rather than a third specific moiety. ${ }^{2}$

Bydgeman et $a l^{5}$ showed that the distribution of $\mathrm{W}$ serogroups differed appreciably in two areas of central Sweden. Stockholm had a higher proportion of WII strains whereas Örebro had a higher

\footnotetext{
Address for reprints: Dr H Young, STD Diagnostic Laboratory, Department of Bacteriology, University Medical School, Teviot Place, Edinburgh EH8 9AG
}

Accepted for publication 16 January 1984 proportion of WI strains. Antibiotic susceptibility of $N$ gonorrhoeae also varies in relation to serogroup; non-penicillinase-producing $N$ gonorrhoeae of serogroup WI were most susceptible and those of serogroup WIII were the most resistant. ${ }^{6}$

A very strong relation between serogroup WII and rectal isolates from men has been shown, ${ }^{78}$ but no correlation has been made between $\mathrm{W}$ serogroups and other anatomical sites of isolation. Moreover the distribution of W serogroups in the United Kingdom has not been reported, although workers in Bristol have shown that the $\mathrm{W}$ serogroup of gonococcal strains was the same from a limited number of contact pairs. ${ }^{9}$

The aim of this study was twofold: to examine the distribution of $\mathrm{W}$ serogroups in the Edinburgh area, and to examine the serogroup of gonococcal strains from male homosexuals in relation to the anatomical site of isolation.

\section{Materials and methods}

\section{CLINICAL ISOLATES}

We obtained 205 gonococcal isolates from patients attending the department of genitourinary medicine at the Royal Infirmary, Edinburgh; 163 were from infections contracted in the Edinburgh area between November 1982 and June 1983, 32 were from infections contracted in Edinburgh during 1981 and 1982 and were preserved as lyophilised cultures before serogrouping, and 10 were from infections contracted abroad between November 1982 and June 
1983. All isolates were identified as $N$ gonorrhoeae by the rapid carbohydrate utilisation test. ${ }^{10}$

\section{STOCK CULTURES}

$N$ gonorrhoeae major outer membrane protein (MOMP) reference strains A-1, B-2, C-3, D-4, E-5, F-6, N-10, R-11, S-12, U-14, and V-15 11 were kindly supplied by Dr D Danielsson, department of clinical bacteriology and immunology, Central County Hospital, Örebro, Sweden. Staphylococcus aureus NCTC8530 was obtained from the National Collection of Type Cultures, Colindale, London. All gonococcal strains were maintained on modified New York City (MNYC) medium. ${ }^{12}$ Staph aureus was maintained on blood agar.

\section{PREPARATION OF ANTISERUM}

Antiserum to each reference strain was prepared as described by Sandström and Danielsson. ${ }^{13}$ Table I shows the strains used for immunisation. Antiserum to S-12 and F-6 was kindly supplied by Dr E Sandström, department of dermatology, Karolinska Institutet, Stockholm, Sweden.

TABLE I Immunisation and absorption scheme for producing antisera for coagglutination reagents

\begin{tabular}{lll}
\hline $\begin{array}{l}\text { Immunising } \\
\text { strain }\end{array}$ & $\begin{array}{l}\text { Absorption } \\
\text { strain }\end{array}$ & $\begin{array}{l}\text { Serogroup defined } \\
\text { by corresponding } \\
\text { coagglutination reagent }\end{array}$ \\
\hline MOMP E-5 & MOMP N-10 & WI \\
MOMP D-4 & MOMP C-3 & WI \\
MOMP V-15 & MOMP C-3 & WI \\
MOMP N-10 & MOMP D-4 & WII \\
MOMP S-12 & MOMP A-1 & WII \\
MOMP U-14 & MOMP R-11 & WII \\
MOMP F-6 & MOMP B-2 \& U-14 & WIII \\
\hline
\end{tabular}

MOMP = major outer membrane protein .

\section{ABSORPTION OF ANTISERUM}

MOMP reference strains used for absorption of the antiserum (table I) were grown on gonococcal (GC) agar (Difco) supplemented with L-glutamine, thiamine pyrophosphate, ferric nitrate, and glucose ${ }^{14}$ for 18 hours, harvested and washed once in $0.01 \mathrm{~mol} / 1$ phosphate buffered saline (PBS) $\mathrm{pH} 7 \cdot 2$. Ten plates gave about $0 \cdot 3-0 \cdot 5 \mathrm{~g}$ wet weight of gonococcal cells. The cells were resuspended in $5 \mathrm{ml}$ PBS, boiled for 30 minutes, and centrifuged at $4000 \times g$ for 20 minutes. The pellet was used for absorption. Equal volumes of antiserum and pellet were incubated at $37^{\circ} \mathrm{C}$ for four hours and then held overnight at $4^{\circ} \mathrm{C}$. The absorbed antiserum was collected by centrifugation, and coagglutination reagents were prepared to test the specificity of the antiserum. Absorption was repeated if cross reactions persisted.

\section{PREPARATION OF COAGGLUTINATION} REAGENTS

This was essentially as described by Jephcott. ${ }^{15}$ Staph aureus NCTC8530 was grown on GC agar for 18 hours, harvested, washed thoroughly in $0.01 \mathrm{~mol} / 1$ PBS ph $7 \cdot 2$, resuspended in PBS containing $0 \cdot 5 \%$ $(\mathrm{v} / \mathrm{v})$ formalin, and incubated at room temperature for three hours. The cells were then washed twice, resuspended in PBS, and heated at $80^{\circ} \mathrm{C}$ for five minutes. The stabilised cells were then washed twice, resuspended to $10 \%(\mathrm{w} / \mathrm{v})$ in $\mathrm{PBS}$, and stored at $-20^{\circ} \mathrm{C}$ in $1 \mathrm{ml}$ aliquots.

\section{PREPARATION OF SENSITISED TEST SUSPENSION}

Absorbed antigonococcal serum $(0 \cdot 1 \mathrm{ml})$ was mixed with $1 \mathrm{ml}$ of washed stabilised staphylococcal cell suspension and held at room temperature for 15 minutes. The cells were then harvested by centrifugation at $2500 \times g$ for 15 minutes and the deposit washed twice in PBS. The sensitised cells were finally resuspended in $10 \mathrm{ml}$ sterile PBS. The control reagent was prepared in exactly the same way, with normal rabbit serum substituted for antigonococcal serum.

\section{TEST PROCEDURE}

Test suspensions of $N$ gonorrhoeae were prepared by harvesting organisms from half a culture plate into $400 \mu \mathrm{l}$ distilled water and boiling for 10 minutes. Tests were performed with $20 \mu$ l test gonococcal suspension and $20 \mu \mathrm{l}$ coagglutination reagent thoroughly mixed on a glass slide and rocked for two minutes. Slides were examined under oblique light against a dark background, and the amount of agglutination with the test reagent compared with that obtained in a similar test with the control reagent. The reactions were graded negative $(-)$ and weakly positive $(+)$, moderately positive $(2+)$, and strongly or very strongly positive $(3+)$.

\section{SEROGROUPING PROTOCOL}

In a pilot study 58 strains were tested with each coagglutination reagent. The coagglutination reagents anti E-5 and N-10, defining serogroups WI and WII respectively, reacted with most of the gonococcal strains within these serogroups. Each test gonococcal strain was therefore thereafter screened against the three reagents anti $\mathrm{E}-5, \mathrm{~N}-10$, and F-6, defining serogroups WI, WII and WIII. When the serogroup of the strain was known, the reaction pattern of the strain with the remaining reagents within its serogroup was assessed. On the few occasions when a cross reaction occurred with anti $\mathrm{N}-10$ and F-6 reagents, the strain was cloned before repeating the serogrouping. 
STATISTICAL ANALYSIS

The $\chi^{2}$ test with Yates's correction was used.

Results

SEROGROUPS OF ISOLATES FROM INFECTIONS ACQUIRED IN THE EDINBURGH AREA

All strains of $N$ gonorrhoeae tested could be serogrouped. Table II shows the reaction patterns obtained in coagglutination tests with local gonococcal isolates: $85(44 \%)$ of all isolates belonged to serogroup WI and $110(56 \%)$ to serogroup WII. Most of the gonococcal strains, $66 \%$ of WI and $73 \%$ of WII, reacted with all three of the reagents defining each group. In addition, some minor reaction patterns were obtained.

None of the 195 gonococcal strains acquired in Edinburgh was grouped as WIII, although a few serogroup WII strains gave equivocal reactions with this reagent. Two strains acquired in West Africa and the Far East were classified as serogroup WIII, and one strain acquired in Thailand was grouped as WII/WIII.

TABLE II Coagglutination serogrouping of 195 gonococcal strains isolated from infections acquired in the Edinburgh area

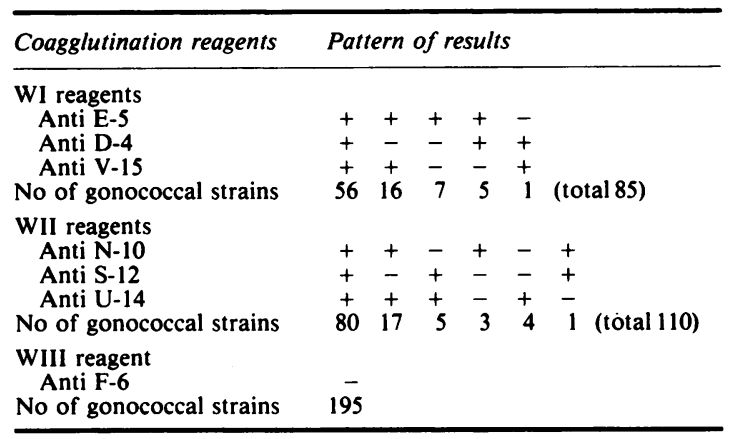

+ = agglutination; - = no agglutination

STRAINS OF $N$ GONORRHOEAE ISOLATED FROM HOMOSEXUAL MEN COMPARED WITH THOSE ISOLATED FROM HETEROSEXUAL MEN AND WOMEN

Table III shows the distribution of the $\mathrm{W}$ serogroups in the three groups of patients. Serogroup WII accounted for $90 \%$ of all isolates from homosexual men and for $34 \%$ and $47 \%$ of isolates from heterosexual men and women respectively. This difference in distribution of serogroup WII between gonococcal isolates from homosexual and heterosexual men was highly significant $\left(\chi_{1}^{2} 36 \cdot 0\right.$; $\mathrm{p}<0.01)$ as was the difference between strains isolated from homosexual men and heterosexual women $\left(\chi_{1}^{2} 25 \cdot 1 ; \mathrm{p}<0 \cdot 01\right)$.
TABLE III Distribution of serogroups WI and WII among homosexual men and heterosexual men and women

\begin{tabular}{lccc}
\hline & \multicolumn{3}{c}{ No (\%) of strains with serogroup: } \\
\cline { 2 - 4 } Patient group & $W I$ & WII & Total \\
\hline Homosexual men & $6(10)$ & $53(90)$ & 59 \\
Heterosexual men & $37(66)$ & $19(34)$ & 56 \\
Women & $42(53)$ & $38(47)$ & 80 \\
Total & $85(44)$ & $110(56)$ & 195 \\
\hline
\end{tabular}

SEROGROUPS OF ISOLATES FROM VARIOUS ANATOMICAL SITES

Table IV shows the serogroups of isolates from various sites. In homosexual men serogroup WII predominated regardless of the anatomical site from which the strain was isolated. Genital, mainly cervical, isolates from women were equally divided between serogroups WI and WII, whereas $69 \%$ of urethral isolates from heterosexual men were in serogroup WI $\left(\chi_{1}^{2} 2 \cdot 6 ; 0 \cdot 5>p>0 \cdot 1\right)$.

TABLE IV Serogroups of isolates from various anatomical sites

\begin{tabular}{|c|c|c|c|}
\hline \multirow[b]{2}{*}{ Patient group } & \multirow{2}{*}{$\begin{array}{l}\text { Anatomical } \\
\text { site }\end{array}$} & \multicolumn{2}{|c|}{ No $(\%)$ of strains in serogroup: } \\
\hline & & $W I$ & $W I I$ \\
\hline Women & $\begin{array}{l}\text { Throat } \\
\text { Rectum } \\
\text { Genitalia } \\
\text { Other }\end{array}$ & $\begin{array}{c}9(50) \\
11(58) \\
21(50) \\
1^{*}\end{array}$ & $\begin{array}{r}9(50) \\
8(42) \\
21(50)\end{array}$ \\
\hline Heterosexual men & $\begin{array}{l}\text { Throat } \\
\text { Urethra }\end{array}$ & $\begin{array}{r}4(50) \\
33(69)\end{array}$ & $\begin{array}{r}4(50) \\
15(31)\end{array}$ \\
\hline Homosexual men & $\begin{array}{l}\text { Throat } \\
\text { Rectum } \\
\text { Urethra }\end{array}$ & $\begin{array}{l}3(19) \\
2(6) \\
1(10)\end{array}$ & $\begin{array}{r}13(81) \\
31(94) \\
9(90)\end{array}$ \\
\hline Total & & $85(44)$ & $110(56)$ \\
\hline
\end{tabular}

*Right hip aspirate

\section{Discussion}

Strains of serogroup WI and WII accounted for $43.5 \%$ and $56.4 \%$ respectively of all the isolates from Edinburgh, or $58 \%$ and $42 \%$ respectively if isolates from homosexual men are excluded. The overall distribution is consistent with data reported from Stockholm which did not distinguish between heterosexual and homosexual men. ${ }^{5}$

In a later study of homosexual male patients in Stockholm, Bydgeman ${ }^{7}$ found that $30(76 \cdot 9 \%)$ of 39 gonococcal strains were of serogroup WII, and this was shown to be an appreciable association. ${ }^{57}$ This considerable association of WII gonococcal strains with male homosexuals has also been noted in Seattle, United States of America. ${ }^{8}$ In our Edinburgh study $53(90 \%)$ of 59 strains isolated from 
homosexual men were of serogroup WII. Our finding of a strong association between serogroup WII and isolates from anatomical sites other than the rectum in homosexual men, suggests that the serogroup antigen is stable once acquired. As transmission of the organism among homosexual men is primarily rectal, it has been postulated that the rectal environment, which is rich in hydrophobic molecules such as faecal lipids, selects gonococcal strains with mutations that reduce the permeability of the outer membrane to hydrophobic molecules. ${ }^{8}$ It seems probable that this same hostile environment selects the particular subgroup of the protein I molecule which is detected by the coagglutination WII reagents. Comparison of the relative distribution of WI and WII strains isolated from the genital regions of male and female heterosexual patients suggests that selective pressures may perhaps be exerted at sites of infection other than the hydrophobic rectal environment.

No WIII strains were isolated from patients infected in Edinburgh, but two such strains were isolated from patients who had contracted their infections in Thailand and Nigeria. This is consistent with other studies, which have shown that WIII strains are uncommon and are generally associated with infections acquired in the Far East. ${ }^{5} 16$

A gonococcal strain has occasionally been classified as serogroup WII/WIII, ${ }^{2}$ which appears to be the result of shared antigenicity between the protein 1B molecules detected by both WII and WIII coagglutination reagents. In this study an isolate from Thailand reacted very strongly with both WII and WIII reagents and was subsequently typed WII/WIII.

Although the coagglutination $\mathrm{W}$ serogroups have been shown to correspond with different outer membrane protein I molecules, it must be remembered that other antigens, such as minor membrane proteins and lipopolysaccharide, probably contribute to the reaction patterns recorded and may be responsible for the equivocal cross reactions seen with some WII strains in tests with the WIII reagent. Cross reactions could also result if a patient was colonised with more than one serogroup. Our data suggest this is unlikely as no cross reactions were observed with the reagents defining the frequently isolated serogroups WI and WII.

Although its precise value has yet to be established, the coagglutination $\mathbf{W}$ serogrouping system is easy and quick to perform and has achieved a more general acceptance than other forms of differentiation between strains.

We thank Professor JG Collee for helpful advice in the preparation of this paper. KGR also gratefully acknowledges the receipt of a Faculty of Medicine Research Scholarship.

\section{References}

1. Sandström E, Danielsson D. Serology of Neisseria gonorrhoeae. Classification by coagglutination. Acta Pathol Microbiol Scand (B) 1980; 88:27-38.

2. Sandström EG, Knapp JS, Buchanan TM. Serology of Neisseria gonorrhoeae: W-antigen serogrouping by coagglutination and protein I serotyping by enzyme-linked immunosorbent assay both detect protein I antigens. Infect Immun 1982; 35:229-39.

3. Sandström EG, Chen KCS, Buchanan TM. Serology of Neisseria gonorrhoeae: coagglutination serogroups WI and WII/WIII correspond to different outer membrane protein molecules. Infect Immun 1982; 38:462-70.

4. Buchanan TM, Hildebrandt JF. Antigen-specific serotyping of Neisseria gonorrhoeae: characterisation based upon principal outer membrane protein. Infect Immun 1981;32:985-94.

5. Bygdeman S, Danielsson D, Sandström E. Serological classification of Neisseria gonorrhoeae by coagglutination: a study of serological patterns in two geographical areas of Sweden. Acta Derm Venereol 1981;61:423-7.

6. Bygdeman S. Antibiotic susceptibility of Neisseria gonorrhoeae in relation to serogroups. Acta Pathol Microbiol Scand (B) 1981;89:227-37.

7. Bydgeman S. Gonorrhoea in men with homosexual contacts: serogroups of isolated gonococcal strains related to antibiotic susceptibility, site of infection, and symptoms. Br J Vener Dis 1981;57:320-4.

8. Morse SA, Lysko PG, McFarland L, et al. Gonococcal strains from homosexual men have outer membranes with reduced permeability to hydrophobic molecules. Infect Immun 1982; 37:432-8.

9. Copley CG, Chiswell CP, Egglestone SI. Neisseria gonorrhoeae: stability of typing markers after natural transmission. Br J Vener Dis 1983; 59:237-41.

10. Young H, Paterson IC, McDonald DR. Rapid carbohydrate utilisation test for the identification of Neisseria gonorrhoeae. Br J Vener Dis 1976;52:172-5.

11. Johnston KH, Holmes KK, Gotschlich EC. The serological classification of Neisseria gonorrhoeae. I. Isolation of the outer membrane complex responsible for serotypic specificity. J Exp Med 1976; 143:741-58.

12. Young $\mathbf{H}$. Cultural diagnosis of gonorrhoea with modified New York City (MNYC) medium. Br J Vener Dis 1978;54:36-40.

13. Sandstróm E, Danielsson D. Serology of Neisseria gonorrhoeae. Characterisation of rabbit hyperimmune antisera by line-rocket immunoelectrophoresis for use in coagglutination. Acta Pathol Microbiol Scand (B) 1980; 88: 17-26.

14. Kellogg DS, Peacock WL, Deacon WE, Brown L, Pirkle CI. Neisseria gonorrhoeae. I. Virulence linked to clonal variation. J Bacteriol 1963; 85: 1274-9.

15. Jephcott AE. Investigation of gonococcal infection. London: Association of Clinical Pathologists, 1981 (Broadsheet 100): $13 \mathrm{pp}$.

16. Bydgeman S, Kallings I, Danielsson D. Serogrouping and auxotyping for epidemiological study of $\beta$-lactamaseproducing Neisseria gonorrhoeae strains isolated in Sweden. Acta Derm Venereol 1981;61:329-34. 